\title{
Preparation and Characterization of Orlistat Bionanocomposites Using Natural Carriers
}

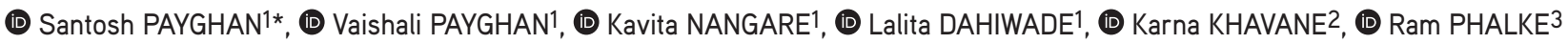 \\ 1Vasantidevi Patil Institute of Pharmacy, Kodoli, Department of Pharmaceutics, Kolhapur, India \\ 2Gurunanak Institute of Pharmacy, Department of Pharmaceutics, Beed, India \\ 3 Tatyasaheb Kore College of Pharmacy, Department of Pharmaceutics, Kolhapur, India
}

\begin{abstract}
Objectives: Bionanocomposites (BNCs) are biopolymers or a natural polymers embedded in a combination of two or more different chemicals using natural carriers or bio. BNCs are widely used in drug formulation and in the development of new drugs for various therapeutic drugs, new dosage forms and in pharmacological medicine.

Materials and Methods: Useful and improved melting was achieved by converting selected Biopharmaceutics Classification System (BCS) class II drug into BNCs using natural carriers such as the gums of Moringa oleifera Lam. and Aegle marmelos (L.) Correa, respectively. The current work focuses on the enhancement of the novel natural polymers such as M. oleifera and A. marmelos, used to prepare BNC for BCS class II orlistat using a microwave system designed for the distribution method. The natural polymer helps improve the melting of the dispersion when it converts them into BNC. Definitions of orlistat, natural carriers, and prepared BNCs were developed and studied comparatively. The fourier transform infrared spectroscopy (FTIR), differential scanning calorimetry (DSC) study revealed that there was no communication between drug associations and environmental carriers.

Results: Crowd reduction studies were conducted to investigate the material that enhances the melting of BNC compounds dissolving and in vitro disposal of BNCs prepared by DSC, scanning electron microscopy, X-ray diffraction studies, and FTIR. BNCs affect orlistat: M. oleifera (OSMOBNC-1: 3), orlistat: A. marmelos (OSAM-BNC-1: 4) is well developed.

Conclusion: Ornat BNCs developed with M. oleifera and A. marmelos provide significant improvements in dissolve and highlight their use in reducing fortification. Additionally, land melting limits were applied and determined for the melting of BNCs prepared using the Hansen Solubility parameters in particular, Hoy's, Fedor and Van Krevelen system and it was found that this report there was a significant increase in the melting of batches prepared for BNCs.
\end{abstract}

Key words: Bionanocomposite, BCS class II, orlistat, Moringa oliefera, Aegle marmelos, microwave-assisted fusion method, Hansen parameters parameter

\section{INTRODUCTION}

The therapeutic efficacy of a drug depends on its availability and ultimately in the formulation of chemicals hydrophilic compounds of the compound and the dissolution of drug molecules. It is a great deal of difficulty in preparing and developing the most effective form of improper water solubility of many drugs. Innocence is a parameter for achieving the desired combination of drugs in the distribution of the system so that the therapeutic response is shown. It is estimated that $40 \%$ or more of the drug molecules identified during the experiment of compounds do not dissolve well in water. There is a need for systematic and simple preparation and structural methods to make less-soluble drugs available. Making these drugs unavailable means that they show enough absorption after oral administration or they may be injected with 3-4 injections. ${ }^{1-5}$

The main purpose of this work is to prepare, mark the structural requirements of the hydrophilic environment, to construct and test the bionanocomposite (BNC) of orlistat with its low water content, reducing its drug absorption, which reflects the Biopharmaceutics Classification System (BCS) class-II drug 
profile. Current work is being done to provide alternative drug delivery with improved solubility and a level of detoxification in the form of nanocrystal drugs that will overcome the problems in the existing dosage form. ${ }^{6}$ Many methods have been used to stabilize moisture, such as salt formation, co-crystallization, co-solvency, hydrotropic, solvating agent and nanotechnology by chemical modification. Under the body modification to reduce particle size, crystal behavior modification, gravity, mixing with surfactants and drug distribution to carriers.

Nanocomposite is a combination of two or more different chemicals that have different properties and blends, to combine these two beautiful structures. The combination has two elements of different textures and the combination of those displays is enhanced in its larger structures. ${ }^{7}$ The body composition of the drug and its natural or bio-carrier compounds are nanotechnology and their experimental parameters, such as in vivo and in vitro profiles and biological detection, are therefore called BNC. ${ }^{8}$ BNC for microwave irradiation can be used in various ways such as improved melting, melting and the availability of drug-soluble drugs. ${ }^{9}$ Microwave radiation contains frequent frequencies between infrared and radio waves, in the range of $0.3-300 \mathrm{GHz}$. It passes through objects and causes their molecules to glide, releasing heat. Microwaves, which can penetrate into anything, allow heat to be produced at any time in the sample at a specific time..$^{10}$

Orlistat is a lipase inhibitor for managing obesity, which functions by inhibiting the absorption of saturated fats. Orlistat is a modified inhibitor of gastric and pancreatic lipase. The orlistat falls under category II according to BCS, which means it exhibits poor oral discretion due to low melting. In this study, the microwave-induced diffusion (MIND) process was used to increase the melting and oral availability of orlistat using Moringa oleifera and Aegle marmelos gum as the leads. Performance tests of the method, physicochemical composition, and in vitro dissolution are presented in this report. The promotion and use of new polymers such as $M$. oleifera and $A$. marmelos gum to improve the melting of orlistat and its converted form through its combination of nano-composition using a microwave-assisted process and the drug spread into a natural gum carrier. Gum carriers, orlistat and integrated BNC were tested for solubility, drug content, solubility, in vitro and spectral readings, and thermal and nanoscale temperatures for BNCs prepared by fourier transform infrared spectroscopy (FTIR), differential scanning calorimetry (DSC), and scanning electron microscopy (SEM)." The rate of melting of the drug and the reduction of the drug for the desired liquid soluble drug does not only reflect the availability of the drug. Additionally, melting was determined using the parameters of Hansen solubility and hildebrand solubility by bringing them closer to various systems such as Hoy's system, Fedor's constant, and Van Krevelen equation. The use of this method in determining the melting of BNC prepared in pharmaceuticals highlights the best systematic approach to obtain the need for the study reported here to ensure the melting of prepared BNCs.
Hansen solubility parameters (HSPs)

Hildebrand and Scott introduced the concept of solubility parameter ( $\delta$ ), which suggested that objects with similar values could be felt (Hildebrand and Scott, 1964) HSP model 1967 predicting liquid reactions, incompatibility of polymer mixtures, soil moisture and pigmentation on HSP surface. After predicting the ineffectiveness of active substances/carriers in the strong distribution of HSPs in medical science. Guessing the compatibility of pharmaceutical materials, and their use is recommended as a tool in pre-construction and tablet development is recommended by HSPs. The study found that drug and substance abuse disorders, as predicted by deceptive tools that could be used, could be used to predict the co-crystal formation, orlistat was selected as an active drug ingredient (API). The group donation methods used to calculate HSPs for conformers and orlistat were used.12-15 The three-component tools used were used to predict the orlistat and conformer irregularities laboratory tests for co-crystals were performed using thermal and fluid-assisted methods in the prediction of inaccuracies. Heat exchangers and powder X-ray diffraction (XRD) were used for co-crystal precision.

$\Delta \mathrm{H}=\mathrm{V}_{\mathrm{T}} \sqrt{(\mathrm{Ev} 1 / \mathrm{Vm} 1)}-\sqrt{(\Delta \mathrm{Ev} 2 / \mathrm{Vm} 2)^{2}} \emptyset 1 . \varnothing 2$

$\Delta \mathrm{H}$ is the heat of mixing, $\mathrm{V}_{\mathrm{T}}$ is the total volume, $\Delta \mathrm{E}_{\mathrm{V}}$ is the energy of vaporization, $V_{m}$ is the molar volume, $\varphi$ is the volume fraction, and 1 and 2 stands for the solute and solvent. The energy of vaporization per unit volume as the cohesion energy density (CED) explained.

$\delta=(C E D)^{0.5}=(\triangle E / V)^{0.5}$

Here, $V$ is the molar volume.

Hansen determined that total cohesion energy is the sum of dispersion $E_{D}$, polar $E_{P}$, and hydrogen bond energy $E_{H}$.

$\mathrm{E}_{\mathrm{T}}=\mathrm{E}_{\mathrm{D}}+\mathrm{E}_{\mathrm{P}}+\mathrm{E}_{\mathrm{H}}$

The total HSP or Hildebrand solubility parameter $\delta$ T by dividing both sides of the equation by molar volume $\mathrm{V}$.

$\delta_{T}^{2}=\delta_{D}^{2}+\delta_{P}^{2}+\delta_{H}^{2}$

Where:

$\delta$ : Total solubility parameters

$\delta$ : Dispersion interactive (London) force

$\delta$ : Permanent dipoles in interacting molecules, called dipole dipole interactive forces

$\delta$ : Hydrogen bonding force

According to equation (1) if $\delta_{\mathrm{T}}$ of both solute and solvent are a like, this will allow predicting solubility. $\left(\mathrm{J} / \mathrm{m}^{3}\right) 0.5, \mathrm{MPa}$ 0.5 or $\left(\mathrm{cal} / \mathrm{cm}^{3}\right) 0.5$, where one $\left(\mathrm{cal} / \mathrm{cm}^{3}\right) 0.5$ is equivalent to $2.0421 \mathrm{MPa} 0.5$ or $\left(\mathrm{J} / \mathrm{m}^{3}\right) 0.5$ are commonly used units for $\delta$ in literature. $\delta$ calculation methods were different between practical and theoretical ones according to either direct/indirect 
measurement of essential properties of material as evaporation temperature, viscosity, solubility in preset solvents, etc. ${ }^{16-19}$

\section{Orlistat testing/prediction for co-crystallization}

Group donation methods are applied to the limits of melting of soluble solvents using Hoys molar attraction constants, Fedor's substants, and Van Kreevalen which are currently used methods. In this study, these methods were used to reach the melting point parameters. The resulting structure has an open combination of chains and open rings are the basic steps of Fedor's method. Then, using the potential possible lumps. This is summarized and the melting point is calculated as the square root of the total energy mixing of the variable elements separated by the number of times the volume of molar substituent constants. The rate of constant molar attraction to the molar volume is expressed by the Hoys process. Drug effects and compounds are compared and their durability status is expressed. The selection of drug-related conformer, group donation method is used in the calculation of the doctrine. HSPs determine whether the drug and conformer are compatible and form the molecular structure of the drug and the conformer. Fedor's, Hoys', and Van Kreevlens's methods of calculation are derived from atomic or molecular attachments to form a structure. These methods are used in the calculations of melting theory.

\section{MATERIALS AND METHODS}

Orlistat was received as a gift sample at INTAS Pharmaceuticals Ltd., (Ahmadabad, and Gujarat, India). The drug was stored in an amber glass container wrapped in aluminum foil and stored in a refrigerator at $5-7^{\circ} \mathrm{C}$. M. oleifera and $A$. marmelos gum were collected from a local garden, Waranananagar. M. oleifera gum was collected by making a hole in the trees (an area damaged by trees). Gum was collected in a suitable air-tight container followed by air drying. Another natural gum, A. marmelos was collected as beal fruit contains a lot of gum, and after breaking, the beal fruit gum was carefully collected in a suitable air container followed by sun and wind suspension. ${ }^{20-23}$

No need to ethical committee approval.

Extraction and purification of natural gum ${ }^{24-28}$

Gums M. oleifera and marmelos collected are dried on the ground under the sun. Dry gum was passed through Sieve no: 80 . Dry gum $(10 \mathrm{~g})$ was stirred in distilled water $(250 \mathrm{~mL})$ for $6-8 \mathrm{~h}$ at room temperature. Through centrifugation, supernatant was obtained and the remains were washed with distilled water. The process was repeated four times. Finally, a precipitant with a strength of more than $500 \mathrm{~mL}$ was twice treated with acetone volume for continuous movement. The products were burned and washed with distilled water and the same products were dried at $50-60^{\circ} \mathrm{C}$ under a machine.

\section{Swelling characteristics}

Measured $10 \mathrm{~g}$ of natural carrier is placed in a measuring cylinder of $100 \mathrm{~mL}$. The first dose of powdered gums was noted, and the cylinder was filled with refined water up to $100 \mathrm{~mL}$. The cylinder was kept aside for $24 \mathrm{~h}$, and the volume of the swollen powder was noted. The inflammation index is expressed as a percentage and is calculated according to the following equation:

$\%$ inflammation $=(\mathrm{Xt}-\mathrm{X} 0) / \mathrm{X} 0 \tilde{\mathrm{A}} \times 100 \ldots$ (3)

There, $X 0$ is the first height of the powder on the graduated cylinder and $\mathrm{Xt}$ refers to the constant height of the swollen gums after $24 \mathrm{~h}$.

\section{Viscosity determination 29,30}

The viscosity of the cleaned gums was determined by taking $1 \mathrm{~g}$ each $M$. oleifera and $A$. marmelos gum, respectively and dispersed in $100 \mathrm{~mL}(1 \% \mathrm{w} / \mathrm{v})$ water. The estimated distribution viscosity was measured by Rheometer (Spindle 3, Brookfield DV-E, Brookfield Engineering Laboratories, Inc., Middleboro, MA, USA).

\section{Foaming index}

The dynamic index of the carrier term is measured to determine the functional properties. One gram of carrier was dispensed in $100 \mathrm{~mL}$ of distilled water and stirred vigorously for $2 \mathrm{~min}$. The overflow index of network company is measured to establish its operational structures. The foam index is calculated using the following equation:

Foam guide $=\mathrm{Vf}-\mathrm{Vi} . .$. (4)

There, $\mathrm{Vf}$ is a $1 \% \mathrm{w} / \mathrm{v}$ solution for network company after a shake and $\mathrm{Vi}$ is a $1 \% \mathrm{w} / \mathrm{v}$ solution for a network company solution before shaking.

\section{Ash value}

Three samples of purified gum were placed on pre-measured crucibles and measured. These are then placed in a preheated oven at $300^{\circ} \mathrm{C}$ for $3 \mathrm{~h}$. The temperature of the furnace then rose to $600^{\circ} \mathrm{C}$ until the hot metal samples were white to ash. Samples were then extracted using lumps and allowed to cool in the desiccators. After cooling, crosses containing the samples were weighed again. The amount of ash obtained by subtracting the combined weight of ash samples and crosses from the combined weight of new samples and crucibles.

Total ash value: $5 \mathrm{~g}$ of purified gum powder was ignited in an electric furnace at $600^{\circ} \mathrm{C}$ in a silica crucible until the sample reached a constant weight.

Water-soluble ash value: Total ash obtained was heated up to $600^{\circ} \mathrm{C}$ with the addition of $25 \mathrm{~mL}$ water for $10 \mathrm{~min}$. It was filtered through whatman paper no. 41 and the residue was ignited in the furnace to get a constant weight.

Acid-insoluble ash value: Total ash obtained was heated with the addition of $25 \mathrm{~mL}$ of $0.1 \mathrm{~N} \mathrm{HCL}$ for $10 \mathrm{~min}$. It was filtered through whatman paper no. 41 and the residue was ignited in the furnace to get a constant weight.

\section{Physical mixtures}

A portable combination of drugs containing natural doses extracted from the gums was prepared in sequence with a simple drug mix with natural carriers in the required dosage (1:1 to $1: 10$ drug:carriers) for $10 \mathrm{~min}$. 
Bionanocomposites by microwave-induced diffusion ${ }^{31-34}$

The preparation of BNC by two groups such as orlistat and $M$. oleifera gum (OSMONC) and A. marmelos gum (OSAMNC) was performed. The clear combination of the drug and the natural agent is made by mixing similar to each sample. Weight loss $(\mathrm{w} / \mathrm{w})$ dose of the drug in the manager is taken as required by the values that maintain the constant value of the combination. After that $4 \mathrm{~mL}$ of water was added to each gram of the drug carrier mixture to form a consistent slurry (water is added to the carrier hydration). The prescribed amount of slurry $(5 \mathrm{~g}$ ) was placed on a glass board with a teflon stirrer (exposed to microwaves) and treated with microwave radiation at various times with a power of $560 \mathrm{~W}$. The temperature of the compound was recorded at the end of the treatment using a built-in temperature test. The samples were then milled in a glass mortar and the same sample was filtered to obtain a particle size of $80-250 \mu \mathrm{m}$.

BNCs were prepared by incorporating the weight-bearing drug orlistat and the M. oleifera and A. marmelos gum carrier at 1:1 to 1:10 w/w size (Table 1). The same physical combination of OS and network company was prepared using mud and a pestle. The slurry was prepared by adding $4 \mathrm{~mL}$ of distilled water to each gram of the drug-carrying compound. A limited amount of slurry ( $5 \mathrm{~g}$ ) was placed in a glass beaker and radiated by microwave radiation at 700 W (IFB Microwave Oven, Model 17 PM-MEC1, Kolkata, India) for continuous operation. Temperature was noted using a temperature measurement built-in within the end of treatment. BNCs were laid using mud and pestle to obtain the required size of $80-250 \mu \mathrm{m}$. The synthetic BNCs of natural-containing orlistat ( $M$. oleifera and $A$. marmelos) vary in the appropriate process for preparing OSMONC and OSAMNC.

\section{Evaluation of bionanocomposite}

Solubility

The melting study of BNCs (OSMONC and OSAMNC) was conducted by adding a higher dose of orlistat (equivalent to 30 $\mathrm{mg}$ ) and BNCs to $150 \mathrm{~mL}$ of distilled bottled water. The resulting mixture was stirred $24 \mathrm{~h}$ at a temperature of $25^{\circ} \mathrm{C}$ using an orbital shaker incubator. The excess liquid was collected and filtered through 0.2 membrane filters and analyzed by a ultraviolet (UV)-visible spectrophotometer of $203 \mathrm{~nm}$ wavelength at 28 sequences. The optimization ratio (drug:carrier) is done on the basis of the best melted detection.

\section{Drug content}

The amount of orlistat added to BNCs such as OSMONC and OSAMNC, was determined by extracting $100 \mathrm{mg}$ of the drug from BNC by diluting it into $25 \mathrm{~mL}$ enough methanol. The resulting solution was filtered through a 0.2 and membrane filter and analyzed by a UV-visible spectrophotometer (UVCarry 60, Agilent) at a wavelength of $215 \mathrm{~nm}$, respectively, against methanol as a blank 8 .

\section{Powder dissolution}

Powdered extraction tests performed on BNCs followed the USP XXIV Apparatus 6 (paddle) method in $900 \mathrm{~mL}$ of dissolved media stored in $37 \pm 0.5^{\circ} \mathrm{C}$ powder containing 5 $\mathrm{mg}$ API added to dehydration sources. $1 \mathrm{~mL}$ sample was withdrawn periodically and the resulting solution was filtered through a $0.2 \mu \mathrm{m}$ membrane filter and analyzed by a UV-visible spectrophotometer (UV-Carry 60, Agilent) at a wavelength of $215 \mathrm{~nm}$, respectively, against methanol as empty 8 . All tests are made in 3 steps. BNC dispersion profiles were compared with the pure drug under similar experimental conditions.

\section{Characterization of bionanocomposites}

A well-defined BNC standardization was performed by FTIR, DSC, XRD, and SEM to ensure the best results of the current drug and polymer study.

\section{Fourier-transform infrared spectroscopy}

FTIR spectra of impure drug (orlistat), pure polymers (M. oleifera and $A$. marmelos gum), and BNCs of individual polymers ( $M$. oleifera and $A$. marmelos gum) were developed to monitor drug compatibility polymer. Drug BNCs with each polymer (OSMOM, OSAMM, were stored directly in the sample holder and scanned using the FTIR spectrophotometer (Cary 60, Agilent Corp., Germany) in terms of drug interactions with the polymer. The materials were scanned in the range from 400 to $4000 \mathrm{~cm}^{-1}$ with 1 at a resolution of $4 \mathrm{~cm}^{-1}$. The peak properties of orlistat, M. oleifera and A. marmelos were compared to BNCs designed to test drug compatibility-polymer. IR detectors were used to determine and predict BNC melting by the HSP.

\section{Differential scanning calorimetry}

DSC studies of orlistat, M. oleifera and A. marmelos gum, and BNCs of drugs with individual polymers (M. oleifera and A. marmelos gum) were conducted to detect improved drug availability. The DSC thermogram was obtained using a scanning calorimeter (DSC 60; Shimadzu) at a temperature of $11^{\circ} \mathrm{C} / \mathrm{min}$ from a temperature of $0^{\circ} \mathrm{C}$ to $250^{\circ} \mathrm{C}$ in an inert state and the physical, chemical interaction between the drug and the polymer that helps determine and predict the melting of BNCs with Hansen parameter.

$X$-ray diffraction studies

XRD studies of drugs (orlistat), pure polymers ( $M$. oleifera and A. marmelos gum), and BNCs of individual polymer drugs ( $M$. oleifera and $A$. marmelos gum) were intended to test changes in crystallinity the drug is mixed with gums. The crystallinity

Table 1. Formulation design for bionanocomposites batches

\begin{tabular}{lcccccccccc} 
Drug + carrier & $1: 1$ & $1: 2$ & $1: 3$ & $1: 4$ & $1: 5$ & $1: 6$ & $1: 7$ & $1: 8$ & $1: 9$ & $1: 10$ \\
\hline OS $^{\mathrm{a}}-\mathrm{MO}^{\mathrm{b}}$ gum & $1: 1$ & $1: 2$ & $1: 3$ & $1: 4$ & $1: 5$ & $1: 6$ & $1: 7$ & $1: 8$ & $1: 9$ & $1: 10$ \\
\hline OS - AMc gum & $1: 1$ & $1: 2$ & $1: 3$ & $1: 4$ & $1: 5$ & $1: 6$ & $1: 7$ & $1: 8$ & $1: 9$ & $1: 10$ \\
\hline
\end{tabular}

${ }^{\mathrm{a} O S}$ : Orlistat, ${ }^{\mathrm{M} M O}$ : Moringa oleifera gum, ${ }^{\mathrm{c}} \mathrm{AM}$ : Aegle marmelos Gum 
property is associated with the physicochemical properties of the material. XRD patterns of orlistat, gums and BNCs were recorded using (Bruker, D8) and Cu-kcy radiation.

\section{Scanning electron microscopy}

The surface morphology of orlistat BNCs was detected by SEM. Samples were placed directly on a two-dimensional SEM adhesive sample and the images were recorded at the required amplification of $15 \mathrm{kV}$ power and $8 \mathrm{~mm}$ working distance on XL30-SFEG Philips (Lab exchange, Burladingen, Germany).

Theoretical prediction of solubility

Fedor's substituent constants

$\delta=\sqrt{\frac{\sum \Delta \Delta U}{\sum \Delta V}}$

Where,

${ }^{*} \Delta \Delta U$ is constant for energy mixing

${ }^{* \star} \Delta \mathrm{V}$ is constant for molar volume

Hoys method/Hoys molar attractions

According to [(cal cc) $\left.1 / 2 \mathrm{~mol}^{-1}\right]$ unit

$\delta=\frac{\sum \text { molarattraction }}{v}$

Van Kreevalen's solubility parameters

The given calculation of solubility parameter and molar volume by Van Kreevalen's method is based on experimental molar volume and measured $\mathrm{cm}^{3} \mathrm{~mol}^{-1}$.

$\delta d=\sum F d / V$
$\delta p=\sqrt{\sum F p^{2} / V}$
$\delta h=\sqrt{\sum U h / V}$
$\delta^{2} T=\sqrt{\delta d^{2}+\delta p^{2}+\delta h^{2}}$

\section{RESULT AND DISCUSSION}

\section{Physical characterization of carriers}

The inflammatory properties and viscosity of M. oleifera and $A$. marmelos gum were low (Table 2). Due to the low viscosity of $M$. oleifera and A. marmelos gum, they were considered for the melting and elimination of selected BCS class-II drugs. Both gums were therefore more efficient and easily exploited in improving the melting and degradation rate of orlistat.

\section{Rheological characterization of gums}

Rheological description of M. oleifera L. A. marmelos was performed using a rheometer R/S-CPS + rheometer with the calibration system: C75-2. Viscosity and thixotropic analysis were performed (Table 3 and Figure 1), low viscosity was obtained. As shown in Figure 2, thixotropic analysis obtained $13.23 \mathrm{~Pa} / \mathrm{s}$ of $A$. marmelos and $17.63 \mathrm{~Pa} / \mathrm{s}$ of $\mathrm{M}$. oleifera gum. Therefore, both gums exhibit stability and help increase the solubility of BCS class-II drugs by preparing its BNCs and can withstand the microwave radiation.
Table 2. Organoleptic and physical characterization of natural gums

\begin{tabular}{|c|c|c|c|}
\hline Sr. no. & $\begin{array}{l}\text { Parameters/ } \\
\text { particulars }\end{array}$ & $\begin{array}{l}\text { Moringa } \\
\text { oleifera }\end{array}$ & $\begin{array}{l}\text { Aegle } \\
\text { marmelos }\end{array}$ \\
\hline & Colour & $\begin{array}{l}\text { Brownish } \\
\text { black }\end{array}$ & $\begin{array}{l}\text { Yellowish } \\
\text { white }\end{array}$ \\
\hline & Odour & Characteristic & Characteristic \\
\hline & Taste & Mucilaginous & Mucilaginous \\
\hline & Swelling index $\pm S D^{a}$ & $19.7 \pm 2.21$ & $20.3 \pm 1.01$ \\
\hline & Foaming index \pm SD & $17 \pm 0.92$ & $16 \pm 0.65$ \\
\hline & Angle of repose & $33^{\circ}$ & $31^{\circ}$ \\
\hline & $\begin{array}{l}\text { Bulk density } \\
(\mathrm{gm} / \mathrm{mL})\end{array}$ & $0.71 \mathrm{gm} / \mathrm{mL}$ & $0.67 \mathrm{gm} / \mathrm{mL}$ \\
\hline & $\begin{array}{l}\text { Tapped density } \\
(\mathrm{gm} / \mathrm{mL})\end{array}$ & $1.23 \mathrm{gm} / \mathrm{mL}$ & $1.25 \mathrm{gm} / \mathrm{mL}$ \\
\hline & $\begin{array}{l}\text { Compressibility index } \\
(\%)\end{array}$ & $47.27 \%$ & $52.71 \%$ \\
\hline & Hygroscopicity & $17 \%$ & $16 \%$ \\
\hline & $\begin{array}{l}\text { Swelling Index } \\
(\mathrm{mL} / \mathrm{gm})\end{array}$ & 19.7 & 20.3 \\
\hline & Loss on drying & $11 \% \mathrm{w} / \mathrm{w}$ & $9 \% \mathrm{w} / \mathrm{w}$ \\
\hline & Total ash & $2.6 \%$ & $3.3 \%$ \\
\hline & Insoluble matter & $0.03 \% \mathrm{w} / \mathrm{w}$ & $0.02 \% \mathrm{w} / \mathrm{w}$ \\
\hline & $\mathrm{pH}$ & 5.5 & 6.5 \\
\hline
\end{tabular}

aAll values are represented as means \pm SD $(n=3), S D$ : Standard deviation

Table 3. Rheological characterization of Aegle marmelos and Moringa oleifera gum

\begin{tabular}{lll} 
Parameter & $\begin{array}{l}\text { Aegle } \\
\text { marmelos }\end{array}$ & $\begin{array}{l}\text { Moringa } \\
\text { oleifera }\end{array}$ \\
\hline Viscosity (Pa.s) & 0.5740 & 1.5442 \\
\hline Torque $(\mathrm{mNm})$ & 0.6772 & 4.1996 \\
\hline Speed $(1 / \mathrm{min})$ & 16.8300 & 16.8302 \\
\hline Shear stress $(\mathrm{Pa})$ & 6.1317 & 38.0230 \\
\hline Shear rate $(1 / \mathrm{s})$ & 50.4901 & 50.4907 \\
\hline Density $\left(\mathrm{g} / \mathrm{cm}^{3}\right)$ & 1.0000 & 1.0000 \\
\hline Angular velocity & 0.0000 & 0.0000 \\
\hline
\end{tabular}

\section{Characterization of the bionanocomposites}

\section{Solubility}

Melting is mainly focused on the use of M. oleifera and $A$. marmelos, which are used to stabilize the moisture content of water-soluble drugs. Melting was performed and expressed in $\mathrm{mg} / \mathrm{mL}$ by the clear combination of the selected BCS class-II drug. It was noted that the melting of a more visible compound than that of orlistat (Figure 3). 
The orlistat insoluble study, conducted by comparisons similar to their body composition with BNCs prepared, found that there was a significant increase in the solubility as the polymer drug dose increased. After the OSMO-BNC ratio of 1:3 and the OSAM-BNC ratio of $1: 4$, there was no clear improvement in melting as shown in Figure 3.

The solubility $(\mathrm{mg} / \mathrm{mL})$ of the prepared BNCS of orlistat with $M$. oleifera and $A$. marmelos was observed to be a well-developed dose of OSMO-BNC (1:03) and OSAM-BNC (1:04) selected after practice melting research. This well-performed measure was then confirmed by the removal of the powder and found to be increasing in melting. Soluble reinforcement of OSMOBNC (1:03) and OSAM-BNC (1:04) is widely available and this is due to the foam index and viscosity profile of M. oleifera and A. marmelos gum, a drug spread in gum form I. Its BNC has a structural modification that is made of a type of hydrophilic drug
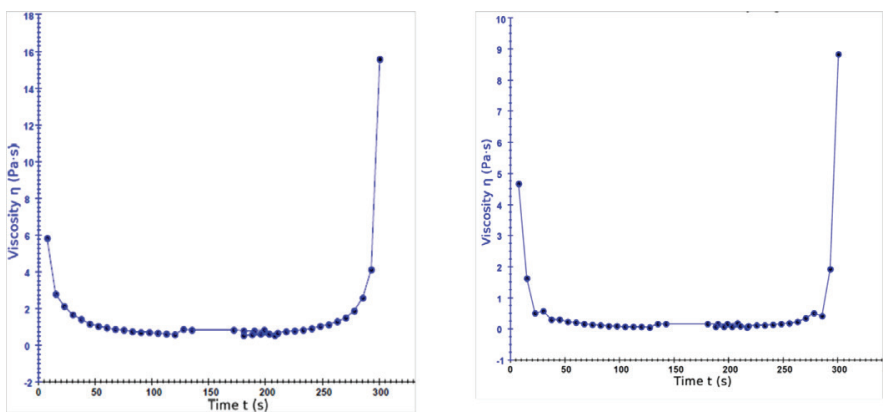

Figure 1. Viscosity diagrams of (A) Aegle marmelos (B) Moringa oleifera
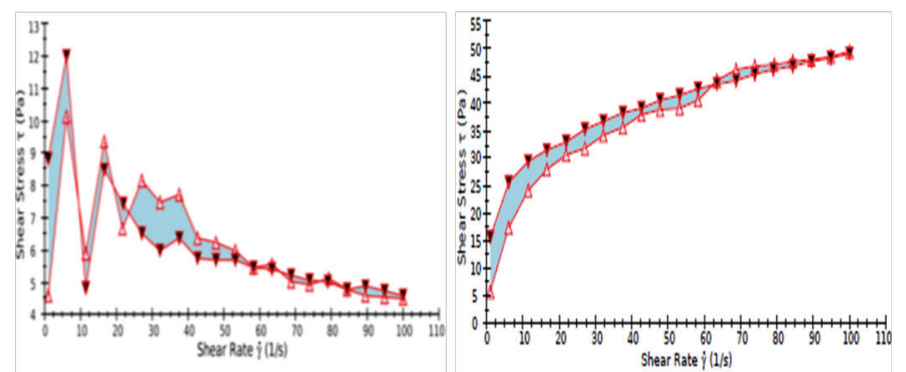

Figure 2. Thixotropic analysis of Aegle marmelos and Moringa oleifera

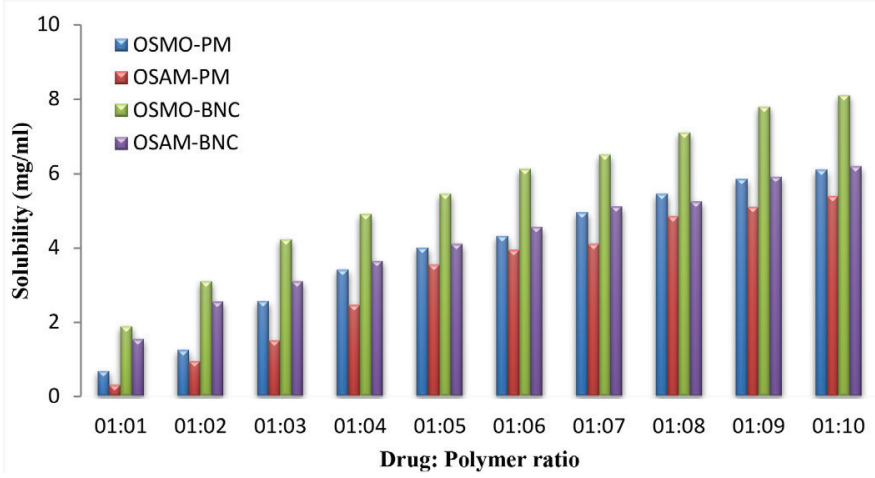

Figure 3. Solubility of orlistat in physical mixture and bionanocomposite with Moringa oleifera and Aegle marmelos (OSMO-PM; OSAM-PM and OSMO-BNC, OSAM-BNC)

OSMO: Orlistat, Moringa oleifera gum, BNC: Bionanocomposite, OSAM: Orlistat, Aegle marmelos enriched with hydrogen bonding and this hydrogen compound helps the molecule disperse and open the rings by producing molar volume without affecting its parental function. This type of hydrophilic has apparently been used to stabilize improper water solubility.

\section{Drug content}

The differential distribution of orlistat in BNCs is determined by the drug content analysis. It was found that $95 \%-98 \%$ of the drugs were trapped in BNCs, showing the same prevalence.

\section{Powder dissolution}

Powder dispersion tests are performed to check the stability of the enhancement components. The degradation profile of the clear compound showed a surprising improvement in the degradation rate compared to orlistat and their clear combination with natural carriers. The combination of orlistat with both gums showed good results. As reported in Figure 4, the dosage of prescription drugs in \% of the pure drug orlistat was found to be $54.69 \pm 4.5$. The combined drug release of OSMO-PM1 body composition was observed $70.2 \pm 7.5 \%$, of OSAM-PM 3 was $61.1 \pm 7.5$ after $60 \mathrm{~min}$.

BNC orlistat with both gums showed good results. As reported, the cumulative drug release in $\%$ of the orlistat was found to be $54.69 \pm 4.5$. The cumulative drug release of BNCS, such as OSMO-BNC was $97.22 \pm 1.1 \%$, for OSAM-BNC was 70.21 $\pm 1.9 \%$ after $60 \mathrm{~min}$ (Figure 5 ). From the observed results, it was clearly shown that the ornate BNCs the orlistat (suggested batches) showed better drug release compared to their pure form and body composition form, it was concluded in the study that a natural polymer was used for microwave BNC included in the separation the dispersion rate is improved in the prepared BNCs.

\section{Characterization of bionanocomposites}

\section{Fourier transform infrared spectroscopy analysis}

FTIR spectroscopy of orlistat shows a high values of 3301.30 (OH simple hydrogen bond), 2918.302 (simple $\mathrm{CH}$ alkanes group), 2853.553 ( $\mathrm{CH}$ stretching alkanes group), 1721.653 ( $\mathrm{C}=0$ carboxylic expansion group), 1665.0 ( $\mathrm{C}=\mathrm{C}$ amide extraction amide), 1201.904 (CO to dilute alcohol), and1841.144 ( $\mathrm{C}=$ Extension

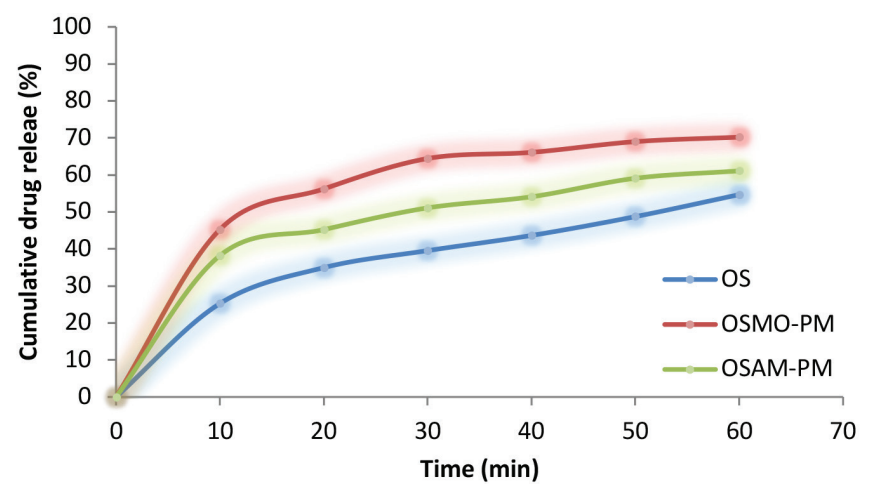

Figure 4. Powder dissolution of physical mixture of orlistat with Moringa oleifera and Aegle marmelos

OS: Orlistat, OSMO: Orlistat, Moringa oleifera gum, OSAM: Orlistat, Aegle marmelos 
of anhydrides) respectively (Figure 6). Whole-gum exudates from $M$. oleifera was found to contain L-arabinose,-galactose, glucuronic acid, and L-rhamnose, -mannose, and xylose, while a single polysaccharide, with a gum polysaccharide containing G-galactose, -glucuronic acid and iron; certain metals such as sodium, potassium, calcium and magnesium; and L-mannose have been found in mild hydrolysis of all acids. For the most part, the gum has frames with large branches that contain different units of sugar with many possible variations in terms of branch level, branch length and type of connection. The IR spectrum (Figure 6) shows a height of 3301 and $3263 \mathrm{~cm}^{-1}$ due to the $\mathrm{OH}$ of the main alcohol extraction. The absorption height of 2928 $\mathrm{cm}^{-1}$ indicates that $-\mathrm{CH}$ extends vibration of the methyl group. $1603 \mathrm{~cm}^{-1}$ bands are a $\mathrm{C}=\mathrm{O}$ element of aldehyde. The height at $1.310 \mathrm{~cm}^{-1}$ is due to the variability of the $\mathrm{CH}_{2}$ equation with the $\mathrm{C}-\mathrm{OH}$ group. Weak bond at $770 \mathrm{~cm}^{-1}$ because $\mathrm{r}$ contributes to

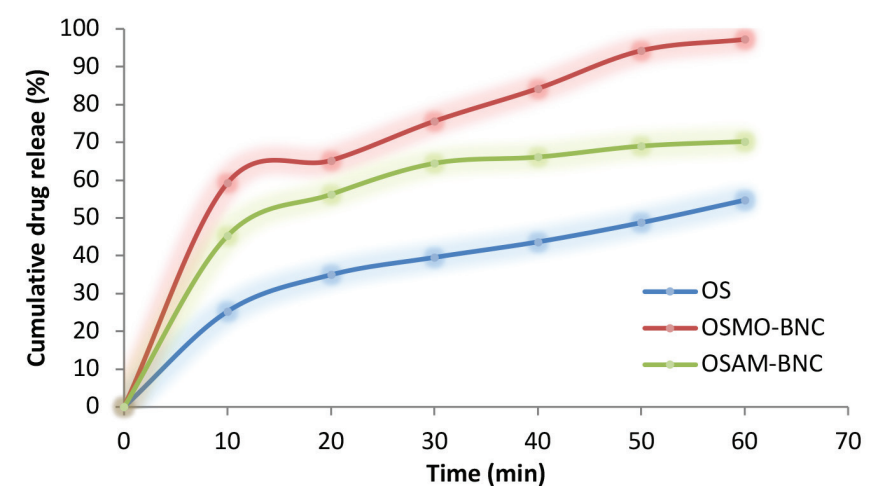

Figure 5. Powder dissolution study of bionanocomposite of orlistat with Moringa oleifera and Aegle marmelos

OS: Orlistat, OSMO: Orlistat, Moringa oleifera gum, OSAM: Orlistat, Aegle marmelos, BNC: Bionanocomposite

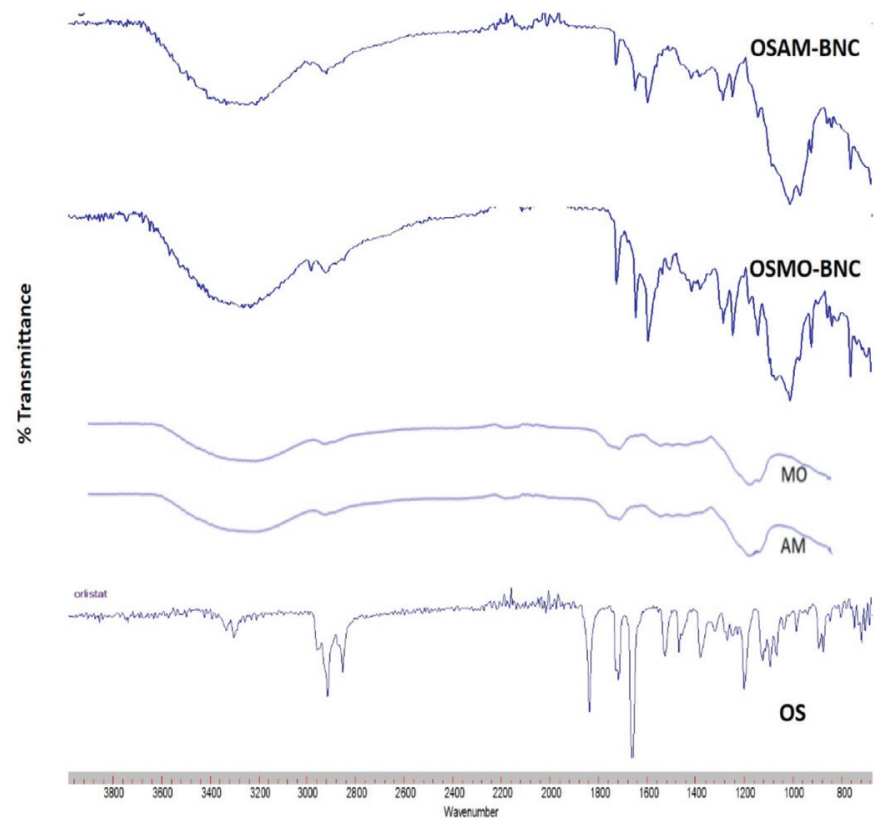

Figure 6. FTIR studies of pure Moringa oleifera (MO) Aegle marmelos (AM), orlistat (OS) and BNCs such as OSMO-BNC, OSAM-BNC

FTIR: Fourier transform infrared spectroscopy, OSMO: Orlistat, Moringa oleifera gum, OSAM: Orlistat, Aegle marmelos, BNC: Bionanocomposite ringing binding and ring flexion of $\alpha-D-(1-4)$ and $\alpha-D-(1-6)$. All of this in conjunction with the polysaccharide structure indicates that, either starch or cellulose, but there were certain peptide cross links and other amino sugars.

Active data of the $A$. marmelos group showed that the major neutral sugars are $\alpha$-D-glucose, $\beta$-D-glucose, and galactose as shown in the composition of osazone. The IR spectrum, shown in Figure 7, indicated to rises to $3296.65 \mathrm{~cm}^{-1}$ due to $-\mathrm{OH}$ to extend the main alcohol. The absorption height at $2977 \mathrm{~cm}^{-1}$ indicated that $-\mathrm{CH}$ extends the vibration of the methyl group. The absence of a large fragrant stretch in the region of 1838 $\mathrm{cm}^{-1}$ and the weakness of the fibers means that there is a limited number of cross-linked peptides. Belts at $1633 \mathrm{~cm}^{-1}$ element $\mathrm{C}=\mathrm{O}$ aldehyde. The height at $1315 \mathrm{~cm}^{-1}$ is due to the variability of the $\mathrm{CH}_{2}$ equation with the $\mathrm{C}-\mathrm{OH}$ group. A weak bond at $821 \mathrm{~cm}^{-1}$ because $r$ contributes to ringing binding and ring conversion of $\alpha-D-(1-4)$ and $\alpha-D-(1-6)$.

\section{Scanning electron microscopy}

SEM research was conducted to look at the surface morphology of the drug particles. Orlistat particles were made of a smooth surface, while OSMO and OSAM particles had unequal shape and size. From this study and writing 7, it is clearly shown that the crystal structure of orlistat was completely changed in OSMO-BNC and OSAM-BNC showing orlistat crystals embedded in the matrix.

\section{Differential scanning calorimetry analysis}

Pharmaceutical DSC thermograms (OS), polymers (M. oleifera and $A$. marmelos) and BNCs for each drug with each polymer are shown in Figure 8. Orlistat DSC showed high endothermic intensity at $51^{\circ} \mathrm{C}$ indicating melting of orlistat. Dimethyl sulfoxide OSMO-BNC and OSAM-BNC showed the same endothermic intensity as that of the pure drugs but with less energy, which may be due to a decrease in the crystal type of drug. A slight change in the melting point showed a reduction of the drug to a nanocrystalline form. The high rate of exposure showed that most of the drug was converted to the nanocrystalline form. No chemical interactions between the drug and the polymer were observed. The physical interaction is the way a drug is bound to a polymer. These studies have confirmed that as the crystalline nanoparticle size of the crystal decreases; its melting point decreases slightly. A slight change in the melting point showed a reduction of the drug to a nanocrystalline form. The high rate
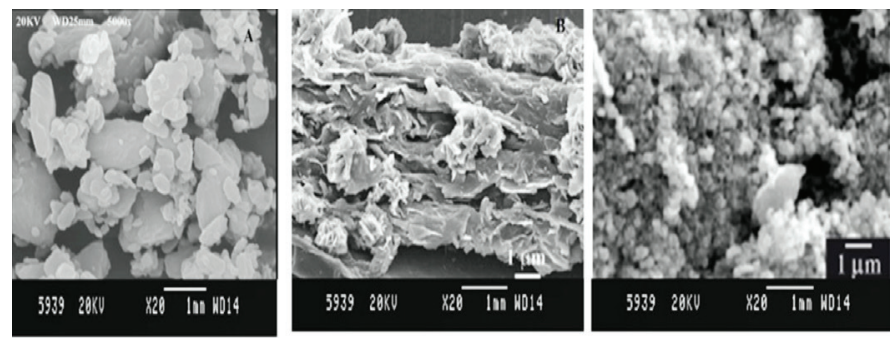

Figure 7. SEM images of orlistat and its BNCs i.e. OSMO-BNC and OSAMBNC with Moringa oleifera and Aegle marmelos ${ }^{26}$

SEM: Scanning electron microscopy, BNCs: Bionanocomposites, OSMO: Orlistat, Moringa oleifera gum, OSAM: Orlistat, Aegle marmelos 
of exposure showed that most of the drug was converted to the nanocrystalline form.

No chemical interactions between the drug and the polymer were observed. The physical interaction is the way a drug is bound to a polymer. These studies have confirmed that as the crystalline nanoparticle size of the crystal decreases; its melting point decreases slightly (Figure 8).

\section{$X$-ray diffraction}

$X R D$ was performed to assess the physical condition of the body and its BNCs. XRD patterns of impure drug (OS), pure polymer (M. oleifera and A. marmelos) and its BNCs are shown
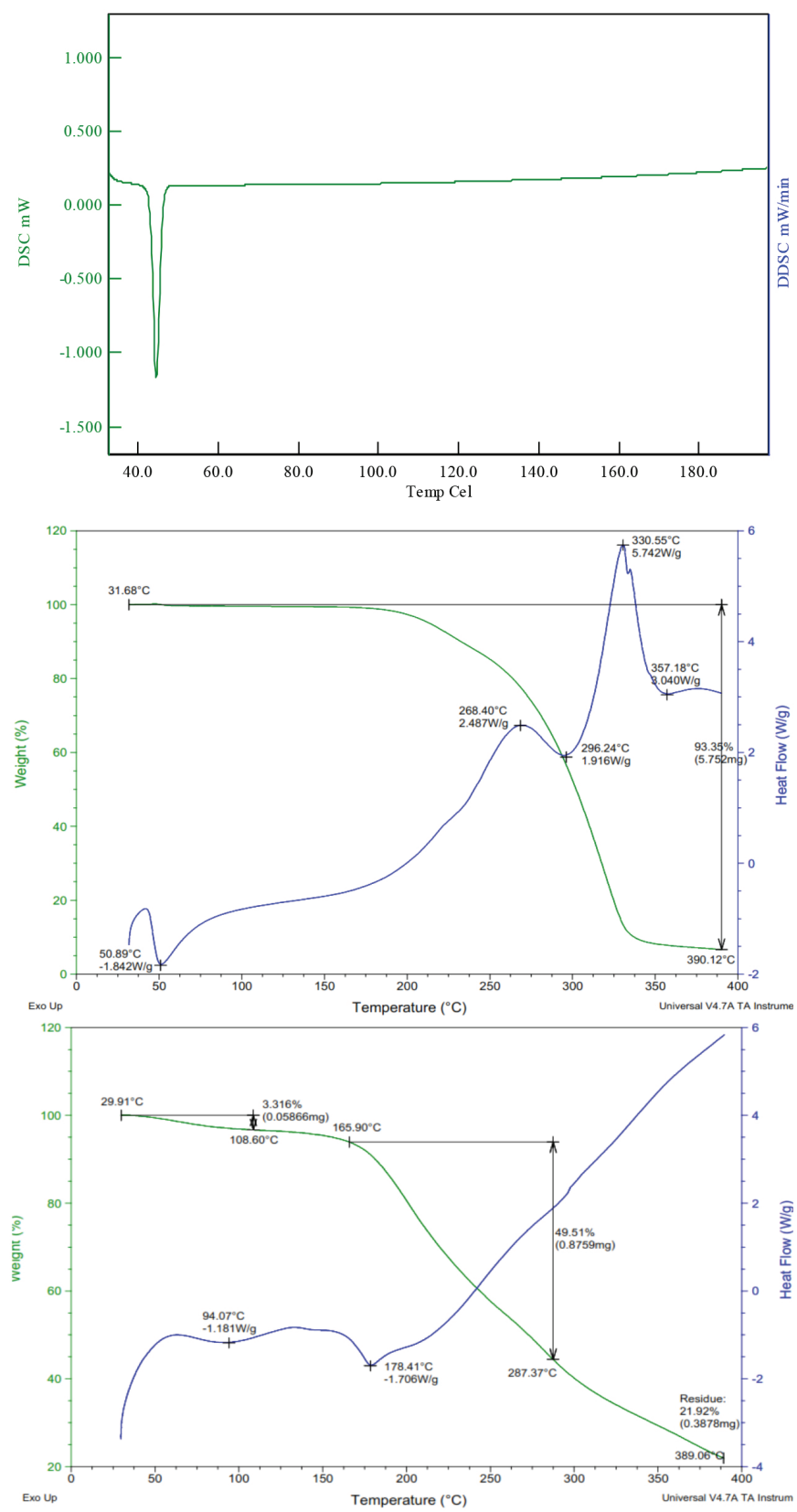

Figure 8. Differential scanning calorimetry of (A) orlistat and its BNCs i.e. (B) OSMO-BNC (C) OSAM-BNC with Moringa oleifera, and Aegle marmelos BNCs: Bionanocomposites, OSMO: Orlistat, Moringa oleifera gum, OSAM: Orlistat, Aegle marmelos in Figure 9. The XRD pattern of pure orlistat showed a high crystalline value between 100 and 600, 14.50, 17.50, 19, 21, 24, $25.50,28,30,32$ and 35 with a very high value of 24 indicating the crystalline form of orlistat. The XRD patterns of OSMONC and OSAMNC showed a significant decrease in elevation due to the decrease in crystallinity. Decreased levels of BNCs may be due to a decrease in drug size to nanolevel.

\section{Theoretical prediction of solubility}

\section{Fedor's method}

Fedor has proposed a method for determining the melting parameter without using the compound density. The contribution of the largest number of active groups has been tested, and the method only requires knowledge of the formula formulation of the combination.

\section{Based on Fedor's succession}

$\delta=V(\Delta \Delta U / A V) ;=(32700) / 37.44)=29.55 \mathrm{H}$

${ }^{*} \mathrm{U}$ always meets a combination of forces

${ }^{* *} \Delta \mathrm{V}$ retains the molar volume

The result obtained from the above calculation of Fedor's stable orlistat was found to be $29.55 \mathrm{H}$. The hydrogen concentration is determined after the opening of the ring in the orlistat structure. The total strength must determine the molecular weight in relation to the molar volume (Table 4).

\section{Orlistat bionanocomposite (OSMO-BNC)}

A modified BNC i.e. OSMO-BNC (orlistat with M. oleifera), where it was considered to dissolve, was found at the time of cracking and in the amount observed in FTIR. There was hydrogen binding possible and the melting parameter helped determine it. Fedor's permanent effect was $11.08 \mathrm{H}$, due to the strong hydrogen bonding in the molecule and the conversion of the other two bonds into bonds that bind together Fedor's BNC orlistat bond also increases and this number of hydrogen bonding increases eventually increases the melting of molecules i.e. smaring constantly in Fedor. Additionally, the molar volume is less representative of their numbers.

\section{Orlistat bionanocomposite (OSAM-BNC)}

The BNCs prepared namely OSAM-BNC (orlistat with $A$. marmelos), when considered for its detection was found at the time cracking and in the amount observed in FTIR. There was a high hydrogen binding and the melting was determined by a parameter, Fedor's continuous effect $\delta$ was $11.56 \mathrm{H}$. Due to excess hydrogen molecular bonding and the conversion of other double bonds to its binding bonds Fedor's constant of BNC, orlistat also increases and this increase in hydrogen bonding ultimately leads to increased molecular melting, which means an increase in Fedor's consistency.

\section{Hoy's method}

The small scheme provided an easy way to measure the amount of solubility parameter in most solvents and polymers. However, the list of constants is not complete. Hoy has published many 
jaw-dropping features found in the pressure points of various groups (Table 5 ).

According to $[(\mathrm{cal} / \mathrm{cc}) 1 / 2 \mathrm{~mol}-1]$ unit

$\delta=\frac{\sum \text { molar attraction }}{V}=\frac{3110.4}{317.958}=9.78 \mathrm{H}$

By using Hoy's formula, the molar attraction for pure orlistat

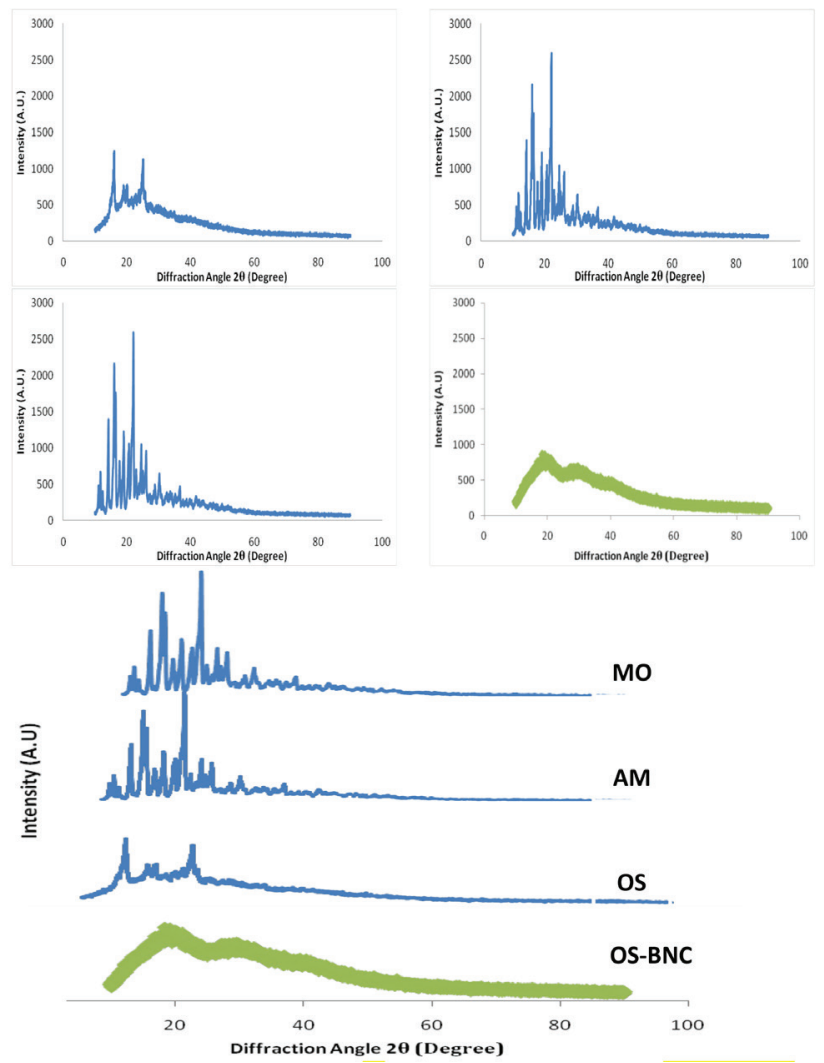

Figure 9. XRD studies of orlistat and its BNCs i.e. OSMO-BNC and OSAMBNC with Moringa oleifera and Aegle marmelos

XRD: X-ray diffraction, BNCs: Bionanocomposites, OSMO: Orlistat, Moringa oleifera gum, OSAM: Orlistat, Aegle marmelos was calculated and it was found $9.78 \mathrm{H}$, where is the sum of the group molar attraction constants of the compound Hoftyzer and Van Kreevalen published a series of group molar attraction constants similar to those of small and Hoy.

\section{Orlistat bionanocomposite (OSMO-BNC)}

By using Hoy's formula, the molar embrace for OSMO-BNC (orlistat with $M$. oleifera) was calculated and found $23.59 \mathrm{H}$ and which more than that of the pure orlistat that was $9.78 \mathrm{H}$.

\section{Orlistat bionanocomposite (OSAMNC)}

By using Hoy's formula, the molar magnetism for OSAMNC (orlistat with A. marmelos) was calculated and found $22.86 \mathrm{H}$, which was more than that of pure orlistat which was $9.78 \mathrm{H}$.

\section{Van Kreevalen's solubility parameters}

Van Krevelen derived Fi values for the assistance of atoms i.e., $\mathrm{C}, \mathrm{H}, \mathrm{N}, \mathrm{O}$, halogens, and statutory effects (such as double or tribal bonds, etc.) solubility parameter $(\delta)$ can be calculated using the following equation:

$\delta=\frac{\sum \mathrm{Fi}}{\mathrm{Vm}}$

where $\Sigma=\mathrm{Fi}$ is the sum of the atomic contributions and $\mathrm{Vm}$ is the molar volume (Table 6).

Calculation of solubility parameter and molar volume of pure orlistat by Van Kreevalen's solubility parameter was obtained $7.71 \mathrm{H}$.

\section{Orlistat bionanocomposite (OSMO-BNC)}

Calculation of solubility parameter and molar volume of OSMONC (orlistat with M. oleifera) by Van Kreevalen's solubility parameter was obtained $8.02 \mathrm{H}$ which is more than the pure form of orlistat i.e. $7.71 \mathrm{H}$.

\section{Orlistat bionanocomposite (OSAM-BNC)}

The calculation of the melting point and molar volume of OSAMNC (orlistat with A. marmelos) by Van Kreevalen's melting

Table 4. Calculation of $\partial$ value of orlistat by F, G, and C methods

Fragments/groups

No of groups $\Delta \Delta U^{*}$ for each (cal.mol ${ }^{-1}$ ) Total $\Delta \Delta U$

$\Delta V^{* *}$ for each $\left(\mathrm{m}^{-1}\right.$ $\left.\mathrm{mol}^{-1}\right) \quad$ Total $\Delta \mathrm{V}$

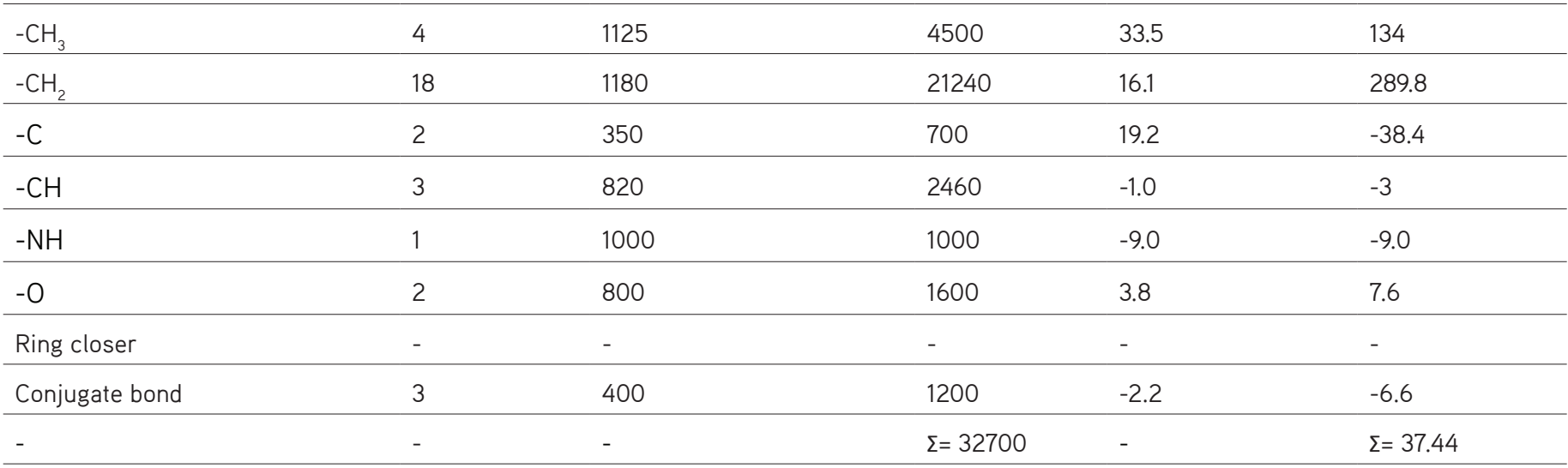


parameter was obtained at $9.9 \mathrm{H}$, which indicates more than the purest form of the drug i.e., $7.71 \mathrm{H}$.

It was noted that the combination of hydrogen with the orlistat molecule was proposed to potentially improve solubility. As the formation of the impact on the established BNCs will be in line with the need to study. A greater number of covalent and hydrogen bonds were formed, when drugs were incorporated into their BNCs and natural carriers.

From the structure obtained, $-\mathrm{O}-\mathrm{OH}$ bond to indicate hydrogen bond and $\mathrm{CH}-\mathrm{OH}$ meaning bond covalent bond and due to such an interaction between selected drugs and gums held in covalent bonds and stated that hydrogen bonding between low energies must break such bond. Additionally, the weak Vander Waals strength found in the prepared BNCs is why the molecular meltdown is enhanced in the proposed way.

\section{CONCLUSION}

Application of natural polymers such as $M$. oleifera and $A$. marmelos for the generation BNC of orlistat by MIND simple, convenient and cost effective method. Further, use of natural carriers influences the physicochemical properties of drug. MIND shows promising approach for enhancing the solubility and dissolution rate of prepared BNCs. The characterization approach using FTIR, XRD, DSC, and SEM explores that orlistat generated into the BNCs showed significant liability to enhance the solubility and increase the dissolution rate. The application of the HSP and hildebrand solubility parameters including Fedor's constant, Hoy's molar attraction, and Van Kreevalen system in prediction and determination of the solubility of prepared BNCs were revealed its utilization in pharmaceutical formulation. It was found that there was significant enhanced solubility of optimized ratios compared with pure entities. Hence, it was concluded here HSP provides acceptable determination of solubility in pharmaceutical science.

Table 5. Calculation of solubility parameter of orlistat based on Hoy's molar attractions

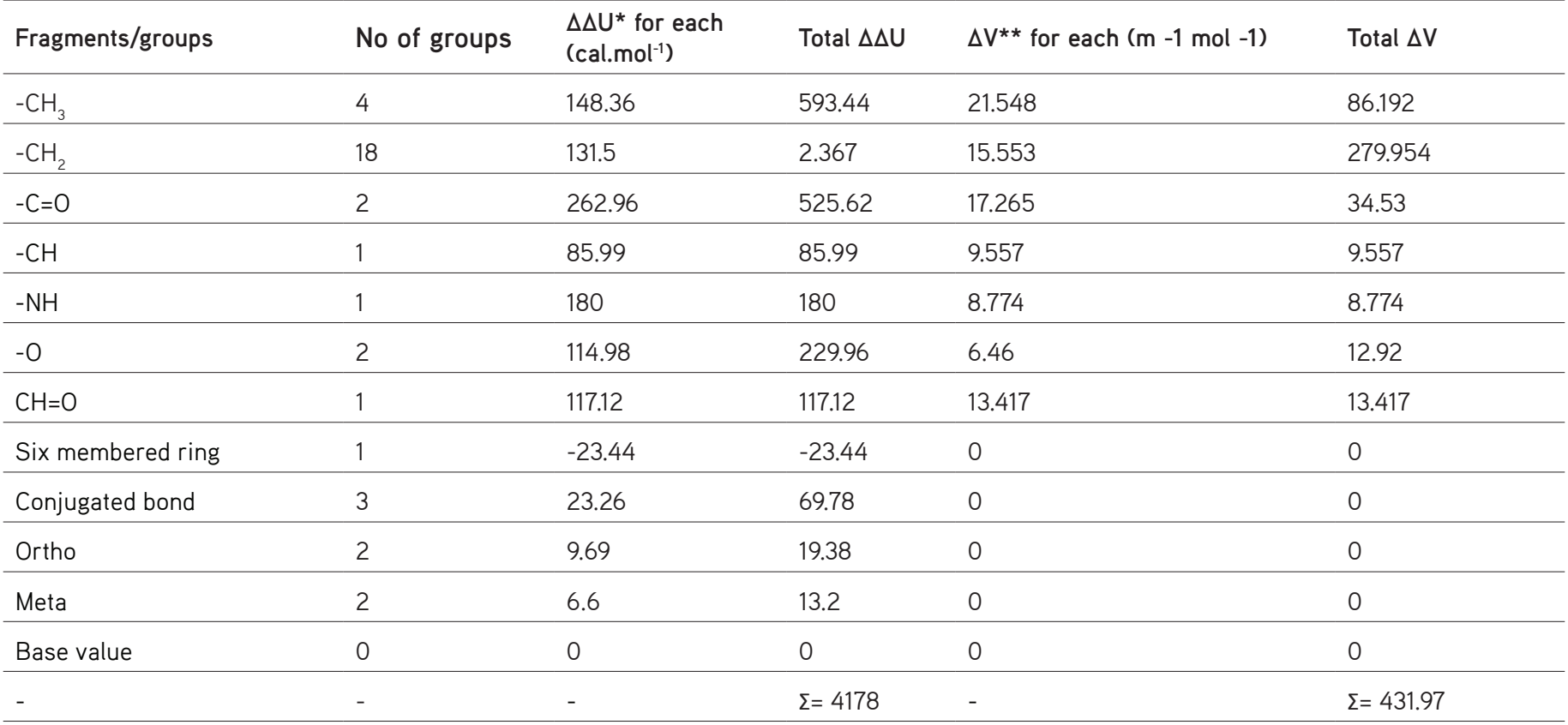

Table 6. Calculation of solubility parameter and molar volume of orlistat by Van Kreevalen's solubility parameter

\begin{tabular}{lllllllll} 
Fragments/groups & No of groups & Fd & Total Fd & Fp & Total Fp & Fp2 & Uh & Total Uh \\
\hline$-\mathrm{CH}_{3}$ & 4 & 420 & 1680 & 0 & 0 & 0 & 0 \\
\hline$-\mathrm{CH}_{2}$ & 18 & 270 & 4860 & 0 & 0 & 0 & 0 \\
\hline$-\mathrm{C}=\mathrm{O}$ & 2 & 0 & 0 & 0 & 0 & 0 & 0 \\
\hline$-\mathrm{CH}_{2}$ & 1 & 80 & 80 & 0 & 0 & 0 & 0 \\
\hline$-\mathrm{NH}$ & 1 & 280 & 280 & 610 & 610 & 372100 & 8400 & 0 \\
\hline$-\mathrm{O}$ & 2 & 100 & 200 & 410 & 820 & 672400 & 3000 & 3000 \\
\hline$-\mathrm{CH}=\mathrm{O}$ & 1 & 200 & 1800 & 0 & 0 & 0 & 0 \\
\hline $6 / 5$ member ring & 1 & 190 & 190 & 0 & 0 & 0 & 0 \\
\hline- & - & - & $\Sigma=8890$ & - & $\Sigma=1044$ & - & - \\
\hline
\end{tabular}




\section{Ethics}

Ethics Committee Approval: Not required.

Informed Consent: Not required.

Peer-review: Externally peer-reviewed.

\section{Authorship Contributions}

Surgical and Medical Practices: S.P., Concept: S.P., Design: S.P., Data Collection or Processing: K.K., L.D., K.N., Analysis or Interpretation: V.P., Literature Search: V.P., R.P., Writing: V.P.

Conflict of Interest: No conflict of interest was declared by the authors.

Financial Disclosure: The authors declared that this study received no financial support.

\section{REFERENCES}

1. Shinde SM, Jadhav CM, Kate VK, Payghan SA, D'souza Jl. Physiochemical assessment of pharmaceutical salt forms: a quality attribute. Int J Pharm Sci Invent. 2014;2:46-53.

2. Pathak CD, Savjani KT, Gajjar AK, Savjani JK. Cocrystal formation of paracetamol with indomethacin and mefenamic acid: an efficient approach to enhance solubility. Int J Pharm Pharma Sci. 2013;5:414419.

3. Payghan SA, Shrivastava DN. Potential of solubility in drug discovery and development. Pharm Rev. www.pharmainfo.net

4. Neha O, Bala P. Advances in solubility enhancement techniques. Int J Pharm Sci Rev Res. 2013;21:351-358.

5. Patwekar SL, Jamkhande P, Gattani SG, Payghan SA. Nanobiocomposite a new approach to drug delivery system. Asian J Pharm. 2016;10(Suppl):646-656.

6. Bhat MR, Sharma S, Derkar GK, Chimkode RM, Payghan SA. Microwavegenerated bionanocomposite for solubility enhancement of nifedipine. Asian J Pharm. 2016;10(Suppl):741-749.

7. Shewale S, Shete AS, Doijad RC, Kadam SS, Patil VA, Yadav AV. Formulation and solid state characterization of nicotinamide-based cocrystals of fenofibrate. Indian J Pharm Sci. 2015;77:328-334.

8. Khabade SS, Chopade SS, Gaikwad ER, Payghan SA. Potential screening of spray dried solid dispersion of orlistat using three dimensional solubility parameter. Asian J Pharm. 2017;11(Suppl):760-772.

9. Payghan SA, Patwekar S, Kate VK, Khavane K, Purohit SS. Pharmaceutical solid polymorphism: approach in regulatory consideration. J Glob Pharma Technol. 2010;1:45-53.

10. Vo $\mathrm{CL}$, Park C, Lee BJ. Current trends and future perspectives of solid dispersions containing poorly water-soluble drugs. Eur J Pharm Biopharm. 2013;85:799-813.

11. Mounika P, Raj SV, Divya G, Gowramma A, Vijayamma G. Preparation and characterization of novel co-crystal forms of fexofenadine. Int $\mathrm{J}$ Innov Pharm. 2015;6:458-463.

12. Mohammad MA, Alhalaweh A, Velaga SP. Hansen solubility parameter as a tool to predict cocrystal formation. Int J Pharma. 2011;407:63-71.

13. Belmares M, Blanco M, Goddard WA 3rd, Ross RB, Caldwell G, Chou SH, Pham J, Olofson PM, Thomas C. Hildebrand and hansen solubility parameters from molecular dynamics with applications to electronic nose polymer sensors. J Comput Chem. 2004;25:1814-1826.

14. Savova M, Kolusheva T, Stourza A, Seikova I. The use of group contribution method for predicting the solubility of seed polyphenols of Vitis vinifera $\mathrm{L}$. within a wide polarity range in solvent mixtures. J Chem Technol Metall. 2007;42:295-300.

15. Martin A, Newburger J, Adjei A. Extended hildebrand solubility approach: solubility of theophylline in polar binary solvents. J Pharm Sci. 1980;69:487-491.

16. Thimmasetty J, Subrahmanyam CVS, Vishwanath BA, Babu S. Solubility parameter estimation of celecoxib by current methods. Asian J Research Chem. 2009;2:188-195.

17. Kopparam M, Subrahmanyam C. V. S, Juturu T, Kumar S. N. Solubility parameter of gatifloxacin and its correlation with antibacterial activity. J Solution Chem. 2012;41:381-391.

18. Gaikwad ER, Khabade SS, Sutar TB, Payghan SA. Preparation and characterization of molecular complexes of fenofibrate cocrystal. Asian J Pharm. 2017;11(Suppl):745-759.

19. Fedors RF. A method for estimating both the solubility parameters and molar volumes of liquids. Polym Eng Sci. 1974;14:147-154.

20. Rathi PB, Mourya VK. Extended hildebrand solubility approach: satranidazole in mixtures of dioxane and water. Indian J Pharm Sci. 2011;73:315-319.

21. Schultheiss N, Newman A. Pharmaceutical cocrystals and their physicochemical properties. Cryst Growth Des. 2009;9:2950-2967.

22. Fukte SR, Wagh MP, Rawat S. Coformer selection: an important tool in cocrystal formation review article. Int J Pharm Pharm Sci. 2014;6:9-14.

23. Shaikh K, Patwekar S, Payghan S, Souza JD. Dissolution and stability enhancement of poorly water soluble drug - lovastatin by preparing solid dispersions. Asian j Biomed Pharm Sci. 2011;1:24-31.

24. Payghan SA, Purohit SS, Shrivastava DN. Non-aqueous emulsion: versatile vehicle for drug delivery. Pharm Rev. 2008. www.pharmainfo.net

25. Nangare KA, Powar SD, Kate VK, Khavane KK, Payghan SA. Nanosuspension: potential applications of nano therapeutics in ocular delivery. Mod Appl Bioequiv Availab. 2018;3:1-10.

26. Nangare KA, Powar SD, Kate VK, Patwekar SR, Payghan SA Therapeutics applications of nanosuspension in topical/ mucosal delivery drug delivery. J Nanomed Res. 2018;7:26-36.

27. Yadav AV, Shete AS, Dabke AP, Kulkarni PV, Sakhare SS. Co-crystals: a novel approach to modify physicochemical properties of active pharmaceutical ingredients. Indian J Pharm Sci. 2009;71:359-370.

28. Sarda A, Powar S, Nangare KA, Payghan SA. Formulation and characterization of sublingual tablet for rapid absorption and taste masking of tenoxicam. Inventi Rapid: Pharm Tech. 2018:29-42.

29. Alexandre M, Dubois P. Polymer-layered silicate nanocomposites: preparation, properties and uses of a new class of materials. Mater Sci Eng. 2000;28:1-63.

30. Sonawane AR, Rawat SS, Bhagyshree K, Marathe R. Crystal engineering of nabumetone by cocrystallization. Int J Pharm Pharm Sci. 2014;3:2229.

31. Sanjay AN, Manohar D, Bhanudas SR. Pharmaceutical cocrystallization: a review. J Adv Pharm Education Res. 2014:4:388-396. 
32. Gaikwad ER, Khabade SS, Sutar TB, Bhat MR, Payghan SA. Three dimensional Hansen solubility parameters as predictors of miscibility in cocrystal formation. Asian J Pharm. 2017;11:302-318.

33. Patel JR, Carlton RA, Needham TE, Chichester CO, Vogt FG. Preparation, structural analysis, and properties of tenoxicam cocrystals. Int $\mathrm{J}$ Pharm. 2012;436:685-706.
34. Laszlo F. Cambridge structural database analysis of molecular complementary in cocrystals. Cryst Growth Des. 2009;9:1436-1443. 